\title{
MODEL KEHARMONISAN DALAM PENDIDIKAN AGAMA ISLAM PADA ANAK KELUARGA TKI; STUDI KASUS PADA KELUARGA TKI DI DESA SUNGONLEGOWO BUNGAH GRESIK
}

\author{
Muttaqin Khabibullah ${ }^{1}$, Zumrotus Sholihah ${ }^{2}$ \\ Institut Agama Islam Qomaruddin Gresik \\ e-mail: 1averoos13@gmail.com, 2zumrotussholihah1989@gmail.com
}

Diterima: 02 Oktober 2019 | Direvisi: 29 Oktober 2019 | Disetujui: 03 November 2019

(C) 2018 Program Studi Pendidikan Agama Islam Fakultas Agama Islam Universitas Islam Malang

\begin{abstract}
This study aims to describe the harmonious model of the relationship between foster parents and children of migrant workers' families in educating them about Islam. This research is a qualitative research with a case study approach. Purposive sampling and snowball sampling techniques were used to determine the informants in this study. The data collection techniques use in depth interviews, participatory observation, and documentaries. While the data analysis technique used is the interactive analysis technique of the Miles \& Huberman model. This study produces a picture that the harmonious model of the relationship between foster parents and children of migrant workers' families in Islamic religious care in the village of Sungonlegowo is shown by: first, Badrus and Kina's attention to the welfare of Taufiq and Tahmid, including the need for food and school. Second, Badrus and Kina are responsive to the needs of Taufiq and Tahmid, namely the need for Smartphones and Motorcycles. Third, Badrus and Kina took the time to do activities with Taufiq and Tahmid, from day to night for Kina, and from afternoon to night for Badrus. Fourth, Badrus and Kina showed enthusiasm for Taufiq and Tahmid's behavior by giving praise and reward. Fifth, Badrus and Kina are sensitive to the emotional needs of Taufiq and Tahmid, namely the love needs of parents.
\end{abstract}

Keywords: Harmony, Islamic Education, TKI Child.

\begin{abstract}
Abstrak
Penelitian ini bertujuan untuk menggambarkan model hubungan yang harmonis antara orang tua asuh dan anak-anak keluarga pekerja migran dalam mendidik mereka tentang Islam. Penelitian ini adalah penelitian kualitatif dengan pendekatan studi kasus. Teknik pengambilan sampel Purposive dan snowball sampling digunakan untuk menentukan informan dalam penelitian ini. Teknik pengumpulan data digunakan dalam wawancara mendalam, observasi partisipatif, dan film dokumenter. Sedangkan teknik analisis data yang digunakan adalah teknik analisis interaktif model Miles \& Huberman. Penelitian ini menghasilkan gambaran bahwa model hubungan yang harmonis antara orang tua asuh dan anak-anak dari keluarga pekerja
\end{abstract}


migran dalam perawatan agama Islam di desa Sungonlegowo ditunjukkan oleh: pertama, perhatian Badrus dan Kina terhadap kesejahteraan Taufiq dan Tahmid, termasuk kebutuhan akan makanan dan sekolah. Kedua, Badrus dan Kina responsif terhadap kebutuhan Taufiq dan Tahmid, yaitu kebutuhan untuk Ponsel Cerdas dan Sepeda Motor. Ketiga, Badrus dan Kina meluangkan waktu untuk melakukan kegiatan dengan Taufiq dan Tahmid, dari siang ke malam untuk Kina, dan dari sore ke malam untuk Badrus. Keempat, Badrus dan Kina menunjukkan antusiasme terhadap perilaku Taufiq dan Tahmid dengan memberikan pujian dan hadiah. Kelima, Badrus dan Kina sensitif terhadap kebutuhan emosional Taufiq dan Tahmid, yaitu kebutuhan cinta orangtua.

Kata Kunci: Keharmonisan, Pendidikan Agama Islam, Anak TKI

\section{Pendahuluan}

Tidak ada yang salah dengan pekerjaan seseorang menjadi TKI (tenaga kerja Indonesia) di luar negeri. Karena selain pekerjaan tersebut mendapat hasil yang banyak, juga bisa membangun rumah yang megah dan kebutuhan hidup lainnya. Namun banyak hal-hal negatif yang terjadi dalam keluarga yang pergi bekerja menjadi TKI keluar negeri. Diantaranya, banyak keluarga yang mengalami keretakan rumah tangga yang diakibatkan oleh kurangnya kasih sayang dan kepercayaan tehadap pasangan suami istri, dan kenakalan remaja dikarenakan kurangnya kasih sayang dan pengawasan orang tua. Anak seperti itu cenderung melakukan hal-hal negatif untuk menghibur dirinya, seperti berfoya-foya, minum-minuman keras, bahkan penyalahgunaan narkoba.

Kebanyakan kasus pada keluarga TKI dapat menimbulkan perbutanperbuatan negatif yang terjadi, terutama pada pembentukan perilaku anak dalam sehari-hari. Pada penelitian ini berfokus pada dua anak kembar yang bernama Taufiq dan Tahmid yang sekarang berusia 16 tahun. Mereka termasuk anak yatim, dan hidup dalam keluarga yang kurang mampu. Karena kehidupan yang sangat sulit dan kebutuhan semakin banyak, ibu dari Taufiq dan Tahmid yang hanya lulusan Madrasah Aliyah harus menjadi tulang punggung keluarga, untuk menghidupi kedua orang tua, dan kedua anaknya tersebut. Dia memutuskan untuk menjadi TKI di Malaysia demi mencukupi kebutuhan keluarga semenjak Taufiq dan Tahmid masih berumur dua bulan. Dan sejak itu pula Taufiq dan Tahmid sampai saat ini di asuh oleh kakeknya yang bernama Badrus dan neneknya yang bernama Kina (Badrus dan Kina, 2019).

Karena kepergian ibunya sebagai TKI di luar negeri, kehidupan keluarga tersebut kurang lengkap tanpa adanya kedua orang tua. Seharusnya kedua anak tersebut dirawat, disayangi, dan mendapat 
perhatian dari kedua orang tua kandungnya, namun tidak dengan kedua anak tersebut. Segala kebutuhan dan semua pendidikan diserahkan sepenuhnya terhadap kakek dan neneknya sebagai orang tua asuh. Mereka dididik dan dirawat kakek dan neneknya sebagaimana orang tua kandung sendiri. Meskipun kakek neneknya hanya penjual jajan di pasar desa, namun begitu banyaknya kasih sayang dan cinta kasihnya terhadap cucunya, sang kakek dan nenek ingin sekali cucunya tersebut menjadi anak yang shalih, pintar, rajin beribadah, dan taat pada orang tua. Kedua anak kembar tersebut di sekolahkan di SDN Sungonlegowo, dan ketika MTs mereka pindah sekolah di MTs al-Asyhar Sungonlegowo. Hingga saat ini mereka tumbuh menjadi remaja berusia 16 tahun sebagai siswa di MA alAsyhar Sungonlegowo.

Meski demikian, Taufiq dan Tahmid mempunyai kepribadian yang berbeda dengan anak-anak TKI yang lain. Dalam pendidikanya, meskipun kedua anak tersebut tidak dikatakan anak yang berprestasi namun mereka merupakan anak yang patuh dan hormat terhadap guru di sekolah tersebut. Seperti ketika diperintah guru untuk melakukan sesuatu mereka enggan menolak, ketika bertemu dengan guru di jalan mereka tidak lupa mengucapkan salam dan mecium tangan guru tersebut. Bahkan dalam hal pergaulan-pun, mereka dikatakan anak yang mudah bergaul. Artinya, mereka mau berteman dengan siapa saja tanpa membeda-bedakan teman, baik kaya atau miskin, pintar maupun biasa-biasa saja. Namun mereka masih bisa menempatkan mana yang baik dan mana yang buruk (Ayun, 2019).

Tidak hanya pendidikan di sekolah saja yang sangat di inginkan orang tua, kakek, dan neneknya, tetapi juga pendidikan agama Islam. Tufiq dan Tahmid mengikuti pendidikan diniyah di langgar Ngaren Sungonlegowo. Tidak hanya di langgar tersebut, mereka dididik keagamaan Islam juga di rumah, termasuk dalam hal sholat lima waktu yang wajib dikerjakan, dan mengaji dirumah dan belajar.

Meskipun keterbatasan pendidikan kakek-nenek tersebut, namun semangat dan sikap pantang menyerah kakek nenek tersebut terhadap cucunya sangat ikhlas dan sabar. Dalam masyarakat, kedua anak tersebut dikenal sebagai anak yang penurut. Seperti sering ada tetangga yang meminta bantuan, mereka dengan senang dan ikhlas membantu meskipun ada atau tidaknya orang yang memberi imbalan. Mereka juga sering membantu neneknya mengantarkan pesanan jajan ke pasar dan ke pembeli. Mereka juga giat dan senang berorganisasi terutama dalam hal keagamaan, 
seperti sering meluangkan waktu untuk ikut tadarus di masjid dan kerap mengikuti group al Banjari ketika mendapat undangan tampil (Faqih, 2019)

Keberhasilan dalam memberikan pendidikan agama Islam kepada Tahmid dan Taufiq tidak dapat dilepaskan dari keharmonisan hubungan yang diupayakan oleh orang tua asuh. Dari gambaran di atas penelitian ini menjadi seksi dan menarik untuk di teliti. Sebab pada umumnya anak yang di tinggal orang tuanya bekerja di luar negeri cenderung memiliki sikap prilaku negatif (asusila). Sementara pada gambaran di atas menunjukkan hal yang berbeda dengan kecenderungan umum. Oleh karena itu dalam penelitian ini, penting untuk mengungkap model keharmonisan hubungan yang diterapkan dalam keluarga tersebut agar dapat dipelajari dan hasil penelitian ini dapat menjadi guidance bagi masyarakat dalam mengasuh anak TKI. Disamping itu penelitian ini juga penting dilakukan untuk memberi gambaran tentang model keharmonisan hubungan orang tua asuh dengan anak TKI agar dapat ditiru dan di terapkan oleh keluarga TKI lainnya sehingga kecenderungan-kecenderungan umum prilaku anak TKI yang negatif dapat di atasi atau setidaknya dapat di minimalisir.

\section{Metode}

Penelitian ini merupakan penelitian kualitatif dengan pendekatan studi kasus. Lokasi penelitian ini adalah salah satu keluarga TKI di Desa Sungonlegowo Kec. Bungah, Kab. Gresik. Melalui teknik purposive sampling dan snowball sampling, informan dalam penelitian ini adalah Kina, Badrus, Taufiq dan Tahmid. Adapun teknik pengumpulan data diantaranya adalah in depth interview, observasi partisipatif, dan dokumenter. Sedangkan teknik analisis data yang digunakan adalah teknik analisis interaktif model Miles \& Huberman yang terdiri dari data collection, data reduction, data display, hingga conclution/drawing/verification.

\section{Pembahasan}

\section{Pendidikan Keluarga Terhadap Anak}

Proses sosialisasi yang paling penting dan mendasar merupakan bagian penting dalam pengasuhan dan pendidikan anak. Sebab proses ini berperan penting dalam mempersiapkan anak menjadi anggota masyarakat yang baik. Anak memiliki banyak arti dan peran yang penting bagi keluarga. Anak dapat menjadi tumpuan harapan keluarga, dan anak dapat menjadi tempat bagi orang tua untuk mencurahkan segala perasaannya, baik perasaan senang maupun sedih. Lebih dari itu orang tua berharap agar anak dapat menjadi generasi penerus keluarga, khususnya orang tua. Dengan demikian, 
anak menjadi dambaan keluarga yang diharapkan dapat menjadi penerus cita-cita keluarga (Koentjoroningrat, 1989; 99).

Pada aspek istilah, konsep pola asuh didefinisikan oleh Kohn yang dikutip oleh Thoha sebagai sikap orang tua dalam berinteraksi dengan anak-anaknya. Sikap-sikap orang tua ini dapat dipahami dari beberapa aspek, diantaranya adalah dari cara orang tua memberikan norma dan aturan kepada anak, cara memberikan reward dan punishment, cara orang tua memberikan kewenangan dan kekuasaan, serta cara orang tua memberikan perhatian dan respon pada berbagai kebutuhan dan keinginan anak (Chabib Thoha, 1996; 110).

Insitusi terkecil di dalam masyarakat adalah keluarga. Keluarga merupakan sekumpulan orang yang memiliki hubungan ikatan perkawinan, kelahiran, dan adopsi untuk menciptakan dan mempertahankan kebiasaan, tradisi, dan budaya serta meningkatkan perkembangan fisik, mental, emosional dan sosial setiap anggota keluarga. Keluarga dapat juga dipahami sebagai individu yang terdiri dari dua atau lebih yang memiliki hubungan darah, ikatan perkawinan, adopsi, hidup dalam kesatuan rumah tangga, berhubungan satu sama lain dalam peranannya dalam menciptakan dan mempertahankan kebiasaan, tradisi, dan budaya. Sebagai unsur terkecil dalam kolektivitas masyarakat, keluarga terdiri dua atau lebih individu yang di dalamnya tercakup ayah, ibu, dan anak. Melalui ikatan perkawinan dan darah, mereka saling terhubung satu sama lain. Selain itu, mereka juga berinteraksi satu sama lain dalam menciptakan dan memproduksi budaya dan meningkatkan perkembangan fisik, mental, emosional, dan sosial bagi setiap anggota keluarga di dalamnya.

Dalam hal ini, Islam memandang orang tua sesungguhnya terbebani dengan pertumbuhan fisik dan psikis atas anaknya. Lebih dari itu orang tualah yang bertanggung jawab untuk membebaskan anaknya dari siksaan api neraka. Hal ini sebagaimana yang dijelaskan dalam Q.S. at-Tahrim ayat 6 yang menggambarkan bahwa setiap individu, dan termasuk orang tua harus berupaya dalam membebaskan diri sekaligus keluarganya dari siksa api neraka. Orang tua, terutama ibu harus menfasilitas asupan makananmakanan yang halal dan baik, serta mendidik anak-anaknya yang disesuaikan dengan perkembangan dan pertumbuhan anak yang diarahkan pada pembentukan akhlak mulia.

Suatu cara terbaik bagi orang tua dalam mendidik anak adalah pola asuh yang digunakan sebagai wujud rasa tanggung jawab terhadap anak. Meski demikian, beberapa ahli menunjukkan pandangan yang lain seperti Sam Vankin (2009) mengutarakan bahwa pola asuh sebagai: 
"parenting is interaction between parent's and children during their care (pengasuhan adalah interaksi antara orang tua dan anak-anak selama pengasuhan mereka)" (Al. Tridonanto, 2014; 5).

Pengertian Vankin ini menunjukkan bahwa pengasuhan yang dilaksanakan oleh orang tua kepada anaknya hanya terbatas selama masa pengasuhan. Sehingga jika masa pengasuhan telah selesai, maka orang tua sejatinya terbebas dari tanggung jawab untuk mengasuh anaknya tersebut. Dengan demikian, dapat disimpulkan bahwa pola asuh orang tua adalah suatu keseluruan interaksi orang tua dan anak, dimana orang tua yang memberikan dorongan pada anak dengan mengubah tingkah laku, pengetahuan dan nilai-nilai yang di anggap paling tepat bagi orang tua agar anak bisa mandiri, tumbuh dan berkembang secara optimal, memiliki rasa percaya diri, memiliki sifat ingin tau, bersahabat, dan berorientasi untuk sukses (Al. Tridonanto, 2014; 5).

Pola asuh yang benar akan melahirkan peserta didik yang berkarakter serta berakhlak mulia. Akhlak yang mulia adalah pondasi awal bagi terciptanya interaksi yang baik diantara orang-orang muslim. Oleh karena itu, seseorang yang dapat mewujudkan hubungan baik tersebut merupakan manusia yang bersih, dan konsisten dalam menjalankan semua perintah, dan larangan Allah swt (Ali Abdul Halim Mahmud, 2004; 12). Cara yang dipakai dalam upaya membantu anak untuk tumbuh dan berkembang adalah pengasuhan yang diwujudkan dengan tindakan merawat, membimbing dan mendidik anak, agar dia dapat memperoleh kemandiriannya. Pada intinya pola asuh merupakan sikap yang dipraktikkan oleh seseorang yang mencakup cara memberi makan, memberikan rangsangan, dan memberi kasih sayang kepada anak agar dapat tumbuh dan berkembang dengan baik.

Relasi yang harmonis antara orang tua dan anak dapat diteladani dari bentuk pengasuhan yang dipraktikkan Nabi Ibrahim, Ya'qub, Nuh dan Luqman yang begitu demokratis. Keharmonisan itu terlihat ketika Nabi Ibrahim As, Nabi Ya'qub As, Luqman berdialog dengan putranya yang penuh dengan 'ibroh sekaligus menunjukkan gambaran tingkat keimanan yang tinggi dari pengasuh dan peserta didik (Nabi Ismail, Nabi Yusuf). Mereka, merupakan orang tua yang bertanggung jawab terhadap perkembangan fitrah dan potensi anaknya.

Dalam pembahasan mengenai potensi, al-Ghazali berpendapat bahwa anak adalah masih suci dan kosong, ia selalu menerima apapun yang ditanamkan kepadanya (Samsul Kurniawan, dan Erwin Mahrus, 2011; 92). Dimana Pendapat ini kemudian dikembangkan oleh filusuf Inggris John Locke (1704-1932) menjadi teori "tabula rasa" atau "optimisme pedagogis". 
"Tabula rasa" yang menggambarkan bahwa anak yang terlahir di dunia diumpamakan seperti kertas putih yang bersih. Pengalaman empirik yang diperoleh dari lingkungan memiliki andil yang besar dalam menentukan perkembangan anak (Barnabib dalam Rini Aziz, 2004; 26). Pengalaman empirik yang ditangkap oleh anak dalam kehidupan didapat dari lingkungan sekitarnya berupa rangsangan yang harus ditanggapi oleh mereka.

Rangsangan ini berawal dari alam bebas yang diciptakan oleh orang dewasa melalui program pendidikan. Potensi, atau yang dalam kajian Islam dikenal dengan terminologi fitrah, Jalaluddin menjelaskan bahwa kata fitrah bisa diartikan suci, atau potensi, baik berupa fisik, psikis, maupun kesadaran dalam menjalankan kebaikan dan keburukan. Potensi ini kemudian memproduksi karakter melalui pengaruh dari lingkungan luar. Pembentukan kepribadian anak dipengaruhi oleh pendidikan yang diberikan oleh orang tua. Sebab, jika stimulant yang diberikan orang tua tersebut positif, maka akan respon yang muncul dari anak akan positif pula. Sebaliknya, jika stimulant yang diberikan oleh orang tua negatif, maka respon yang diberikan anak akan negatif pula. Berkaitan dengan hal ini, Miskawih menjelaskan bahwa karakter seseorang dapat berubah sesuai dengan stimulan yang diberikan melalui pendidikan. Oleh karena itu, pendidik harus mampu membimbing dan membiasakan perilaku anak agar sesuai dengan perintah agama.

Dalam dimensi pengasuhan orang tua, menurut pandangan Baumrind bahwa pengasuhan orang tua memiliki dua dimensi yaitu dimensi kontrol dan dimensi keharmonisan. Dalam dimensi kontrol ini, orang tua berharap agar anak memiliki kematangan dan perilaku yang bertanggung jawab. Baik itu berupa kontrol yang jelas yaitu berupa hukuman, maupun kontrol yang samar yaitu melalui pemberian pujian dan hadiah. Dimensi kontrol mempunyai lima sisi peran yang diantaranya adalah: pertama, pembatasan (restrictiveness), yaitu sebagai tindakan pencegahan yang ingin dilakukan anak yang ditandai dengan adanya larangan pada anak. Dalam pemberian larangan ini, orang tua dapat memberi batasan tanpa disertai penjelasan mengenai tindakan yang boleh dilakukan, dan tindakan yang tidak boleh dilakukan. Dengan pemberian larangan ini, anak dapat menilai batasan tersebut sebagai bentuk penolakan atau bentuk ketidaksenangan (Sri Lestari, 2012; 59).

Kedua, tuntutan (demandingeness), yaitu adanya tuntutan berarti orang tua mengharapkan dan berusaha agar anak dapat memenuhi standar tingkah laku, sikap dan tangggung jawab yang tinggi atau yang telah 
ditetapkan. Tuntutan yang diberikan orang tua tersebut bervariasi tergantung sejauh mana anak memperoleh hukuman jika perilaku anak tidak sesuai dengan yang diharapkan. Namun hukuman tersebut tanpa disertai penjelasan dimana letak kesalahan anak, sehingga orang tua yang menerapkan tuntutan sewenang-wenang akan akibatkan anak tidak memiliki sikap mandiri dan cenderung lemah dalam mengadakan kontak positif dan bersosialisasi terhadap teman sebayanya (Al. Tridonanto, 2014; 8). Ketiga, sikap ketat (stricness), yaitu orang tua menerapkan kedisiplinan dengan memberikan batasan-batasan yang berlebihan terhadap prilaku anak. Sehingga anak cenderung tertekan dan merasa terikat oleh tuntutan orang tua.

Keempat, campur tangan (intrusiveness), yaitu sikap dimana orang tua cenderung selalu ikut atau masuk ke dunia anak dalam memantau semua aktifitas dan tindakan anak, orang tua selalu merasa ingin tau apa saja yang dikerjakan oleh anak dalam berbagai kegiatan, akibatnya anak merasa kurang keleluasaan bertindak, dan merasa selalu diawasi orang tua. Kelima, kekuasaan yang sewenang-wenang (arbitrary exercise of power), yaitu sikap dimana orang tua cenderung bertindak sewenang-wenang dan memaksakan kehendak terhadap anak.

Sedangkan dalam keharmonisan atau kasih sayang memiliki beberapa aspek yang berperan diantaranya: pertama, perhatian orang tua terhadap kesejahteraan anak; kedua, responsifitas orang tua terhadap kebutuhan anak; ketiga, waktu luang untuk kegiatan bersama anak; keempat, menunjukkan antusias pada perilaku yang ditunjukkan anak; dan kelima, peka pada kebutuhan emosional anak.

\section{Pendidikan Agama Islam Keluarga TKI}

Untuk menggambarkan keharmonisan dalam pengasuhan pendidikan agama Islam yang diterapkan oleh Badrus dan Kina kepada Taufiq dan Tahmid, maka pada bagian ini terlebih dahulu perlu bagaimana mereka mememberikan pengasuhan Islam kepada Taufiq dan Tahmid. Untuk itu, perlu mengidentifikasi dan mendeskripsikan masing-masing unsur atau komponen pendidikan agama Islam yang diberikan oleh Badrus dan Kina kepada Taufiq dan Tahmid.

Taufiq dan Tahmid merupakan peserta didik utama dalam kajian ini. Kedua anak ini memiliki karakter yang hampir sama. Beberapa karakter mereka berdua adalah: pertama, penurut. Karakter ini merupakan sifat dasar dari Taufiq dan Tahmid yang telah ada sejak mereka kecil hingga dewasa. Meski terkadang atau beberapa kali mereka berdua tidak menuruti kemauan Badrus dan Kina, namun hal itu tidak dapat menurunkan persepsi 
Badrus dan Kina bahwa mereka berdua adalah anak yang penurut. Contoh dari karakter ini yang ditunjukkan oleh Taufiq dan Tahmid adalah kemauan mereka untuk membantu Kina dalam mengantarkan dagangan jajannya ke pasar setiap pagi yang terletak di pertigaan perbatasan antara dusun Ngaren dengan dusun Sungonlegowo.

Kedua, semangat tinggi. Karakter semangat tinggi ini sering kali ditunjukkan oleh Taufiq dan Tahmid baik di rumah, di sekolah, maupun di masyarakat. Beberapa contoh karakter ini yang ditunjukkan oleh Taufiq dan Tahmid di rumah adalah semangat untuk berangkat sekolah pada jam pagi. Selain itu, di rumah Taufiq dan Tahmid juga menunjukkan semangatnya untuk belajar tanpa diperintah, meskipun sekali-dua kali mereka berdua malas belajar. Sementara itu, di sekolah semangat tinggi ditunjukkan oleh Taufiq dan Tahmid dengan perilaku datang ke sekolah dengan lebih awal dan disiplin tinggi. Selain itu, juga ditunjukkan dengan tindakannya dalam ubrak-ubrak teman-temannya untuk sholat berjamaah ketika waktu shalat jama'ah dluhur di mulai. Sedangkan di masyarakat, semangatnya yang tinggi ditunjukkan oleh Taufiq dan Tahmid dengan aktif mengikuti kegiatan latihan shalawat al Banjari dan tadarrus al Quran ketika bulan Ramadlan.

Ketiga, empati. Karakter empati ini ditunjukkan oleh Taufiq dan Tahmid dalam merawat Kina yang saat ini mulai sakit-sakitan. Dalam merawat Kina, Taufiq dan Tahmid-lah yang menyuapi, memakaikan pampers, dan meminumkan obat. Meski demikian, setelah selesai merawat Kina, Taufiq dan Tahmid sering bersedih dan menangis. Sebab keduanya merasa tidak tega dan kasihan atas kondisi Kina yang mulai sakit-sakitan. Diantara Taufiq dan Tahmid, yang lebih tegar adalah Taufiq, sementara Tahmid seringkali menangis dihadapan Kina ketika merawatnya. Sementara Taufiq biasanya menangis setelah merawat Kina.

Keempat, memiliki passion dibidang kesenian Islam. Taufiq dan Tahmid memiliki bakat dan minat dibidang kesenian Islam, yakni kesenian rebana shalawat al Banjari. Karena itulah, Taufiq dan Tahmid aktif mengikuti kegiatan latihan dan tampil rebana shalawat al Banjari bersama santrisantri di langgar pesantren at Thahiriyah yang dikelola oleh K.H. Muhadi Zein (Badrus dan Kina, 2019).

Secara umum pengasuhan agama Islam yang dipraktikkan oleh Badrus dan Kina kepada Taufiq dan Tahmid diarahkan agar mereka berdua menjadi anak yang rajin, dan pandai, baik dalam ilmu umum maupun agama seperti rajin sholat lima waktu, rajin mengaji dan mengetahui apa yang dilarang dan apa yang tidak dilarang, menghormati orang yang lebih tua, pentingnya tali silaturrokhim dan pentingnya bekerja keras (Badrus dan 
Kina, 2019). Untuk mengarahkan kepada tujuan ini, Taufiq dan Tahmid dididik agama Islam dalam berbagai lingkungan, diantaranya adalah lingkungan keluarga, lingkungan sekolah, dan lingkungan masyarakat. Sebab Badrus maupun Kina menyadari berbagai keterbatasannya dalam memberikan pengajaran agama Islam kepada kedua anak asuhnya, baik aspek pengetahuan, waktu luang, dan pengalaman keagamannya.

a. Lingkungan Keluarga

Di lingkungan keluarga, pengasuh utama yang memberikan pendidikan agama Islam adalah Badrus dan Kina yang merupakan kakek dan neneknya sendiri. Materi agama Islam yang diajarkan oleh Badrus dan Kina sebagai orang tua asuh kepada Taufiq dan Tahmid meliputi materi fiqih, akhlaq, dan al Quran. Materi fiqih yang diajarkan Kina dan Badrus berupa fiqih Ibadah, yang meliputi: sholat tepat waktu, mengajarkan niat dan tata cara puasa ramadlan. Sedangkan pembelajaran akhlak yang diajarkan kina dan badrus meliputi: keharusan menghormati guru, menuruti perintah orang tua, disiplin dalam ibadah dan ssekolah, membiasakan silatur rohim dengan keluarga dan sesama, disiplin dalam belajar, memberi pengalaman dan kesadaran dalam bekerja keras (Badrus dan Kina, 2019).

Adapun pembelajaran materi al Qur'an yang diajarkan Kina dalam rumah yaitu meminta Taufiq dan Tahmid untuk mengaji baik di madrasah diniyah, TPQ, maupun mengaji sendiri dirumah bersama-sama Kina dan Badrus. Banyak cara yang diajarkan oleh Kina dan Badrus agar Taufiq dan Tahmid mau menuruti perintahnya baik itu dengan memberi pujian, nasehat bahkan dengan upah. Apapun akan dilakukan oleh kina dan badrus agar taufiq dan tahmid terbiasa dengan hal- hal yang baik dan bisa menerapkan kebaikan tersebut dalam kehidupan sehari-hari, sehingga Taufiq dan Tahmid menjadi pribadi yang beraklakul karimah (Badrus dan Kina, 2019).

b. Lingkungan Sekolah

Di lingkungan sekolah, Taufiq dan Tahmid disekolahkan di MTs dan MA al Asyhar Sungonlegowo Bungah Gresik. ${ }^{1}$ Di MTs al Asyhar Sungonlegowo materi agama islam yang diajarkan kepada Taufiq dan Tahmid meliputi: al Qur'an, hadits, fiqih, aqidah, SKI, bahasa arab, nahwu, shorof, aswaja, dan seni kaligrafi Islam. Adapun materi agama islam yang diajarkan kepada Taufiq dan Tahmid di MA al Asyhar Sungonlegowo meliputi al Qur'an, hadits, fiqih, aqidah, SKI, bahasa arab, aswaja, faraid,

${ }^{1}$ Saat ini Taufiq dan Tahmid sudah menginjak kelas 11 jurusan IPA di MA Al Asyhar Sungonlegowo Bungah Gresik 
tahsin al Qur'an, dan seni kaligrafi Islam (Taufiq dan Tahmid, 2019). Di sekolah al Asyhar ini beberapa pendidik yang mengajarkan agama Islam diantaranya adalah: Ilmiyatin Zaqiyah yang mengajar al Qur'an, K.H. Qosim Matan yang mengajar BMK (bimbingan baca kitab), Zainal Abidin yang mengajar bahasa Arab, Bisrun Hamidun yang mengajar Aswaja an Nahdliyah, Muhadi Zain yang mengajar aqidah dan akhlaq, H. Midhar Ahsan yang mengajar seni kaligrafi Islam, Safari yang mengajar fara'id (ilmu waris), Uswatun Hasanah yang mengajar nahwu-shorof, Sholikhuddin SKI (sejarah kebudayaan Islam), dan Amiroh Zain yang mengajar ilmu Qira'ah (Taufiq dan Tahmid, 2019).

c. Lingkungan Masyarakat

Di lingkungan masyarakat, terdapat sejumlah lembaga yang dijadikan Kina dan Badrun sebagai tempat untuk mengajarkan agama Islam kepada Taufiq dan Tahmid. Beberapa diantaranya adalah: Madrasah Diniyah Mifthaul Ulum, dan Pesantren at Thahiriyah. Di Madrasah Diniyah Miftahul Ulum materi agama Islam yang diajarkan adalah membaca kitab kuning, dan membaca al Qur'an (Taufiq dan Tahmid, 2019). Pendidik utama yang mengajarkan agama Islam kepada Taufiq dan Tahmid di Madrasah diniyah ini adalah Nur Kholifah yang mengajar kitab kuning, dan Ifa yang mengajar al Quran dengan metode ummi di rumah $\mathrm{H}$. Thalabi (Taufiq dan Tahmid, 2019).

Sedangkan di Pesantren at Thahiriyah Taufiq dan Tahmid belajar kesenian hadrah dan shalawat al Banjari. Taufiq dan Tahmid belajar kesenian ini di langgar pesantren at Thahiriyah yang diasuh oleh Muhadi Zein bersama santri-santri lainnya. Di pesantren ini yang mengajari Taufiq dan Tahmid kesenian al Banjari adalah anak dari ibu Sru'ah (Badrus dan Kina, 2019). Taufiq dan Tahmid memiliki minat dan bakat dalam mempelajari kesenian al Banjari ini. Sebab hal ini menurutnya adalah hiburan yang dapat menenangkan hatinya di tengah kesedihan atas ketidaktahuan dan jauhnya jarak mereka dari oring tua kandungnya. Selain di pesantren at Tahiriyah, Taufiq dan Tahmid juga mengikuti ekstra banjari di sekolahan. Baik di sekolahan, di pesantren at Thahiriyah maupun di masyarakat grup al-banjari yang beranggotakan Taufiq dan Tahmid didalamnya sering mendapat tawaran untuk melantunkan sholawat-sholawat baik itu acara rutinan dibaiyah setiap hari Sabtu malam Minggu di musholah at Tohiriyah, acara walimatul ars maupun acara lomba-lomba, dan tidak hanya di desa sendiri bahkan tawaran itu datang dari luar desa maupun luar kota, seperti baru-baru ini grup 
banjari Taufiq dan Tahmid dapat undangan tampil di desa Manyar, sampai ke kota Sidoarjo (Taufiq dan Tahmid, 2019).

\section{Model Keharmonisan Keluarga TKI dalam Pendidikan Agama Islam}

Baurmind menjelaskan bahwa keharmonisan dalam pengasuhan adalah upaya menciptakan suasana menyenangkan dalam hubungan keluarga. Dimensi keharmonisan memiliki beberapa aspek yang berperan diantaranya: pertama, perhatian orang tua asuh terhadap kesejahteraan anak; kedua, responsifitas orang tua asuh terhadap kebutuhan anak; ketiga, orang tua asuh meluangkan waktu untuk melakukan kegiatan bersama anak; keempat, orang tua asuh menunjukkan antusias terhadap tingkah laku yang ditampilkan anak; dan kelima, orang tua asuh peka terhadap kebutuhan emosional anak (Sri Lestari, 2012; 59). Keharmonisan hubungan dalam pengasuhan agama Islam oleh Badrus dan Kina sebagai pengasuh kepada Taufiq dan Tahmid sebagai anak asuh menunjukkan kondisi cukup baik dengan pemenuhan kelima aspek sebagaimana yang ditunjukan Baurmind.

Kondisi keharmonisan hubungan Badrus dan Kina dengan Taufiq dan Tahmid dapat digambarkan dengan perhatian Badrus dan Kina terhadap kesejahteraan Taufiq dan Tahmid melalui pemenuhan kebutuhan fisologis mereka agar keduanya dapat belajar agama Islam dengan baik. Kebutuhan fisiologis yang dimaksud dalam hal ini adalah pemenuhan kebutuhan pangan, sandang, dan papan. Dari sekian banyak kebutuhan Taufiq dan Tahmid, kebutuhan yang paling diperhatikan oleh Badrus dan Kina adalah pola makan. Pola makan Taufiq dan Tahmid biasanya makan tiga kali dalam satu hari, yaitu pagi, siang, dan sore. Namun, dari ketiga waktu makan tersebut, paling susah bagi Badrus dan Kina adalah menyiapkan makan pagi. Sebab sering kali makanan yang dimasak belum matang. Karena itu, Badrus dan Kina biasanya berinisiatif untuk membelikan makanan di pasar yang terletak di pertigaan perbatasan dusun Ngaren dengan dusun Sungonlegowo. Beberapa makanan yang biasanya dibelikan dipasar untuk Taufiq dan Tahmid diantaranya adalah rujak lontong, bubur, atau yang lain. Hal ini harus dilakukan oleh Badrus dan Kina lantaran jika Taufiq dan Tahmid tidak makan atau sarapan pagi, mereka enggan berangkat kesekolah. Berkaitan dengan hal ini Kina bercerita:

"adekmu iku nek gak sarapan, gak gelem sekolah. (adikmu itu, jika tidak sarapan, tidak mau sekolah) (Kina, 2019)"

Badrus dan Kina juga memperhatikan kebutuhan Taufiq dan Tahmid lainnya, yaitu kebutuhan pendidikan bagi keduanya (Badrus dan Kina, 2019). Untuk menfasilitasi kebutuhan tersebut, pada usia kanak-kanak 
Badrus dan Kina menyekolahkan Taufiq dan Tahmid di Taman KanakKanak al Kautsar Ngaren Sungonlegowo. Adapun ketika Taufiq dan Tahmid menginjak usia tujuh tahun, mereka disekolahkan di SDN 2 Sungonlegowo. Taufiq dan Tahmid sengaja disekolahkan ke sekolah tersebut selain karena biaya lebih murah, juga karena lokasinya lebih dekat dengan rumah Badrus dan Kina. Sehingga mereka berdua dapat dengan mudah memantau aktivitas kedua anak asuhnya tersebut. Sebab Badrus sendiri setiap harinya sibuk bekerja sebagai tukang bangunan, sementara Kina setiap hari harus mengantar jajan ke pasar dan menunggu toko peracangan yang ada dirumahnya. Sedangkan pada usia remaja, Taufiq dan Tahmid disekolahkan di MTs al Asyhar Sungonlegowo. Meski agak jauh dari rumah, namun sekolah ini adalah sekolah yang terdekat dengan sekolah lainnya. Selanjutnya, setelah lulus dari MTs al Asyhar Sungonlegowo, Taufiq dan Tahmid melanjutkan sekolahnya di MA al Asyhar Sungonlegowo hingga saat ini menginjak kelas 11 dengan pilihan jurusan IPA. Ditambah lagi Taufiq dan Tahmid di difasilitasi untuk belajar privat tiap habis mahrib kepada Teti yang masih memiliki ikatan sanak-family dengan Badrus dan Kina.

Dalam mendukung proses pendidikan Taufiq dan Tahmid, Badrus dan Kina menyediakan segala kebutuhan sekolah mereka. Beberapa diantaranya adalah SPP, peralatan sekolah seperti : buku, tas, pensil ,seragam, sepatu dan lainnya tidak lupa juga uang saku setiap sekolah. Tindakan dalam memenuhi kebutuhan Taufiq dan Tahmid ini bagi Badrus dan Kina amatlah penting. Sebab mereka merasa kasihan dan iba kepada Taufiq dan Tahmid karena sejak kecil mereka jauh dari kasih sayang orang tua kandungnya. Sehingga Badrus dan Kina sudah menganggap Taufiq dan Tahmid layaknya anaknya sendiri.

Gambaran perhatian Badrus dan Kina ini mempertegas penjelasan Baumrind bahwa perhatian orangtua terhadap kesejahtaraan anak meliputi pemenuhan segala sesuatu yang dibutuhkan oleh anak, baik jasmani maupun rohani. Kebutuhan ini menurut Baumrind meliputi kebutuhan jasmani dan rohani. Misanya, kebutuhan sandang, pangan, dan papan. Selain itu juga pemenuhan kebutuhan seperti kasih sayang, perhatian, rasa aman, dan nyaman juga dibutuhkan oleh anak.

Adapun pada aspek responsifitas orang tua asuh pada kebutuhan anak ditunjukkan oleh Badrus dan Kina dalam memenuhi kebutuhan Taufiq dan Tahmid terhadap Smartphone, dan Motor (Badrus dan Kina, 2019). Semua kebutuhan ini dipenuhi oleh Badrus dan Kina dengan cara meminta kiriman uang kepada ibu kandungnya Tahmid dan Taufiq. Smartphone dibelikan oleh Badrus dan Kina, karena Taufiq dan Tahmid membutuhkan 
Smartphone agar dapat berkomunikasi dengan kakek dan neneknya serta teman sebayanya, disamping juga untuk bermain game. Dengan Smartphone tersebut Kina dan Badrus dengan mudah menghubungi Taufiq dan Tahmid, dan memudahkan Taufiq dan Tahmid untuk menghubungi temannya jika ada latihan Banjari bersama. Sementara itu, kebutuhan Taufiq dan Tahmid pada sepeda motor adalah agar bisa digunakan untuk menghadiri undangan tampil dalam pentas kesenian al Banjari ke luar desa Sungonlegowo. Sebab group al Banjari yang diikuti oleh Taufiq dan Tahmid sering kali mendapat undangan tampil, baik dalam hajatan pernikahan, tasyakuran, lomba-lomba al Banjari dan sebagainya. oleh Karena itu, Taufiq dan Tahmid dibelikan oleh Badrus dan Kina masing-masing satu motor. Meski motor yang dibelikan adalah motor bekas seharga masing-masing 4 juta (jika ditotal 8 juta), namun yang penting bagi Badrus dan Kina adalah mereka dapat memenuhi kebutuhan kedua anak asuhnya.

Perhatian dan harapan Badrus dan Kina dalam memenuhi kebutuhan Taufiq dan Tahmid ini pada faktanya bertentangan dengan kondisi Badrus dan Kina yang serba kekurangan. Sebab mereka memerlukan uang yang cukup banyak untuk memenuhi hal tersebut. Oleh sebab itu, jalan keluar yang bisa dilakukan oleh Badrus dan Kina adalah meminta bantuan dari orang tua Taufiq dan Tahmid untuk mengirimkan sejumlah uang untuk membantu Badrus dan Kina dalam membiayai kebutuhan Taufiq dan Tahmid. Seperti SPP, peralatan sekolah, uang saku sekolah, termasuk membelikan HP dan motor untuk Taufiq dan Tahmid.

"jika memenuhi kebutuhan mereka dengan mengandalkan uang kiriman dari orang tuanya adikmu (Taufiq dan Tahmid) dan juga tambahan dari hasil kerja sendiri supaya adikmu (Taufiq dan Tahmid) merasa senang, nyaman, dan merasakan kasih sayang seperti dari orang tua sendiri (Badrus dan Kina, 2019)"

Gambaran responsifitas terhadap kebutuhan ini yang digambarkan oleh Badrus dan Kina ini mempertegas penjelasan Baumrinda bahwa dalam merespon kebutuhan anak, orang tua hendaknya peka dan cepat merespon terhadap apa yang dibutuhkan anak, terlebih lagi apa yang dibutuhkan anak adalah hal yang dapat menunjang pertumbuhan dan perkembangannya. Kepekaan dalam merespon kebutuhan secara cepat ditunjukkan oleh Badrus dan Kina dalam memenuhi kebutuhan Taufiq dan Tahmid terhadap HP dan Motor. Sementara yang berkaitan dengan pertumbuhan dan perkembangan Taufiq dan Tahmid, Badrus dan Kina meresponnya dengan memberikan fasilitas pendidikan yang layak bagi mereka berdua.

Sementara itu, pada aspek waktu luang bagi anak ditunjukkan oleh Badrus dan Kina dengan meluangkan waktu setiap hari untuh merawat 
Taufiq dan Tahmid adalah ba'da dluhur sampai hendak tidur malam. Sebab ba'da dluhur merupakan waktu bagi Taufiq dan Tahmid untuk pulang dari kegiatan belajar di sekolahnya. Sementara Badrus memberikan waktu luangnya bagi Taufiq dan Tahmid pada waktu sore hari hingga menjelang Taufiq dan Tahmid tidur. Waktu luang yang diberikan kepada Taufiq dan Tahmid lebih banyak diberikan oleh Kina daripada Badrus. Hal ini disebabkan karena Badrus mulai pagi hingga sore, harus bekerja sebagai tukang bangunan. Sementara Kina setiap harinya hanya disibukkan untuk menjaga toko peracangan yang berada di depan rumahnya yang dikelolanya sendiri. Oleh karena itu, dapat digambarkan bahwa dalam kesehariannya Kina lebih banyak beraktivitas di rumah dari pada Badrus yang lebih banyak keluar rumah untuk bekerja (Badrus dan Kina, 2019).

Penyediaan waktu luang oleh Kina maupun Badrus bagi Taufiq dan Tahmid dilakukan agar dapat memantau perkembangan dan aktivitas Taufiq dan Tahmid sehari-hari. Pemantauan yang paling penting bagi Badrus dan Kina adalah memastikan bahwa Taufiq dan Tahmid telah menjalankan shalat lima waktu secara istiqamah dan tepat waktu. Selain itu, juga memastikan bahwa Taufiq dan Tahmid telah berangkat menuju TPQ untuk belajar mengaji al Qur'an. Dalam proses pemantauan yang dilakukan oleh Kina maupun Baadrus dilakukan melalui dua pola, yaitu pola pemantauan jarak dekat dan jarak jauh (Badrus dan Kina, 2019).

Pada pola pemantauan yang pertama (jarak dekat), biasanya dilakukan oleh Badrus maupun Kina dengan cara menemani Taufiq dan Tahmid bermain di dalam rumah, menemani menonton televisi, dan menemani bermain di teras rumah. Sedangkan pola pemantauan yang kedua (jarak jauh) biasanya dilakukan oleh Badrus maupun Kina dengan cara mengunjungi tempat atau rumah teman-teman Taufiq dan Tahmid yang sering mereka kunjungi. Dan untuk memantau perkembangan taufiq dan tahmid disekolah, kina tidak pernah absen untuk menanyakan kepada guruguru yang mengajar taufiq dan tahmis di al-asyhar sungonlegowo.seperti ibu h.lailatun niswah, bapak muhadi zain, ani yang sebagai tat usaha di sekolah tersebut. Pola yang kedua ini bagi Badrus dan Kina merupakan tindakan yang harus mereka lakukan untuk memastikan bahwa mereka telah menunaikan kewajiban sholat. Sebab jika Taufiq dan Tahmid bermain terlalu jauh, dihawatirkan mereka akan lupa melaksanakan shalat. Hal lain yang tidak kalah pentingnya bagi Badrus dan Kina adalah memastikan bahwa Taufiq dan Tahmid tidak salah dalam pergaulan dengan temantemannya. 
Gambaran waktu luang yang disediakan oleh Badrus dan Kina diatas mempertegas penjelasan Baumrind bahwa pemberian waktu luang bagi ini hendaknya diberikan sejak usia dini. Hendaknya orangtua dapat menyediakan waktu bersama anak untuk melakukan interaksi yang bermakna atau berkualitas sesuai dengan apa yang dibutuhkan anak yang meliputi kebutuhan anak dalam asih, asuh dan asah. Tidak adanya interaksi antara orangtua dan anak secara langsung dapat menimbulkan efek yang negatif untuk anak, dimana anak akan sulit untuk beradaptasi di lingkungannya. Dengan pemberian waktu luang oleh Badrus dan Kina sejak Taufiq dan Tahmid kecil inilah, menjadikan adanya interaksi yang hangat diantara mereka, sehingga Badrus dan Kina dapat membantu Taufiq dan Tahmid untuk dapat berinteraksi dengan lingkungannya.

Adapun pada aspek rasa antusias pada tingkah laku yang ditampilkan anak juga diwujudkan oleh Badrus dan Kina melalui pemberian penghargaan kepada Taufiq dan Tahmid. Penghargaan tersebut diwujudkan oleh Badrus dan Kina dalam bentuk pujian dan upah kepada Taufiq dan Tahmid (Badrus dan Kina, 2019). Pujian seringkali disampaikan Badrus maupun Kina kepada Taufiq dan Tahmid, terutama ketika meminta bantuan kepada mereka, seperti mengantar jajan ke pasar, membeli sesuatu, mengantar pergi dan sebagainya. Salah satu contoh pujian yang biasa diberikan Kina kepada Taufiq dan Tahmid sebagai berikut.

"anak-e wes gede, lho wes dadi anak pinter gelem ngewangi mak (anaknya sudah besar, sudah jadi anak pintar mau bantu mak [sebutan nenek]) (Kina, 2019)"

Sementara itu, pemberian upah seringkali diwujudkan ketika Kina meminta Taufiq dan Tahmid mengantar jajan ke pasar untuk dijual. Terutama setiap bulan Ramadhan hampir setiap hari Taufiq dan Tahmid kerap mengantarkan dagangan neneknya tersebut ke penjual takjil di sepanjang jalan di desa Sungonlegowo. Meskipun dengan upah 2000, namun itu sudah menyenangkan bagi Taufiq dan Tahmid. Hal ini dilakukan oleh Kina untuk memberikan pelajaran bagi mereka berdua, bahwa jika ingin memperoleh uang atau kesejahteraan ekonomi, maka mereka harus giat bekerja.

Gambaran pemberian antusias yang dilakukan oleh Badrus dan Kina ini mempertegas penjelasan Baumrind bahwa pemberian antusias dapat dilakukan dengan merespon secara hangat apa yang telah dilakukan anak dan memberikan nasehat yang dapat diterima anak jika anak sedang melakukan kesalahan.

Sedangkan pada aspek kepekaan terhadap kebutuhan emosional anak, ditunjukkan oleh Badrus dan Kina dengan memberikan perhatian dan kasih 
sayang yang besar kepada Taufiq dan Tahmid. Sebagaimana telah diketahui bahwa Taufiq dan Tahmid merupakan dua anak yang sejak bayi berusia 2 bulan telah ditinggal oleh orang tua kandungnya pergi ke Malaysia untuk bekerja. Karena itu, sejak masih bayi hingga saat ini mereka belum pernah bertemu, dan merasakan kasih sayang secara langsung dari kedua orang tua kandungnya. Karena alasan inilah Badrus dan Tahmid merasa harus peka dan tanggap terhadap kebutuhan emosional Taufiq dan Tahmid. Kepekaan terhadap kebutuhan emosional ini, diwujudkan oleh Badrus dan Kina dengan jalan memberikan perhatian lebih dan kasih sayang yang besar kepada Taufiq dan Tahmid dengan menganggap mereka berdua layaknya anaknya sendiri meskipun pada faktanya Badrus dan Kina adalah kakek dan nenek mereka (Badrus dan Kina, 2019).

Sejak kecil hingga usia sekitar 15 tahun, Taufiq dan Tahmid sudah mengetahui siapa ibunya, namun Taufiq dan Tahmid belum mengetahui siapa bapaknya. Meski demikian Taufiq dan Tahmid belum pernah sama sekali menanyakan perihal siapa bapak kandungnya, dimana keberadaannya, apakah masih hidup atau sudah meninggal. Namun memasuki usia 16 tahun Taufiq dan Tahmid beberapa kali menanyakan halhal tersebut kepada Badrus dan Kina. Kina menceritakan pertanyaan Taufiq dan Tahmid tentang keberadaan bapaknya sebagai berikut.

"Mak, bapak iku nang ndi mak?, sek urip ta?. Nek wes mati kuburane nak ndi mak?. tak paranane. (Nek, bapak dimana nek?, masih hidupkah?. Jika sudah meninggal dunia kuburannya dimana nek?. Aku akan nyekar ke kuburannya) (Badrus dan Kina, 2019)"

Gambaran kepekaan terhadap kebutuhan emosional anak yang ditunjukkan oleh Badrus dan Kina ini mempertegas penjelasan Baumrind bahwa kurang pekanya orangtua terhadap kebutuhan emosional ini, dikhawatirkan anak akan mengalami depresi dan sulit menyesuaikan diri dilingkungannya kelak. Sehingga sangat penting bagi orangtua untuk dapat peka terhadap kebutuhan emosional anak. Meskipun sempat mengalami depresi karena ketidaktahuan Taufiq dan Tahmid tentang keberadaan bapaknya, namun kepekaan Badrus dan Kina terhadap kebutuhan emosional Taufiq dan Tahmid dapat membuat mereka tidak lagi depresi mengenai jati diri mereka.

\section{Kesimpulan}

Model keharmonisan hubungan orang tua asuh dengan anak keluarga TKI dalam pengasuhan agama Islam di desa Sungonlegowo ditunjukkan dengan adanya: pertama, perhatian Badrus dan Kina terhadap kesejahteraan Taufiq dan Tahmid, diantaranya kebutuhan makan, dan sekolah. Kedua, Badrus dan Kina responsif terdahadap kebutuhan Taufiq 
dan Tahmid, yaitu kebutuhan terhadap Smartphone dan Motor. Ketiga, Badrus dan Kina meluangkan waktu untuk melakukan kegiatan bersama Taufiq dan Tahmid, mulai siang sampai malam bagi Kina, dan muali sore hingga malam bagi Badrus. Keempat, Badrus dan Kina menunjukkan antusias terhadap tingkah laku Taufiq dan Tahmid dengan pemberian pujian dan reward. Kelima, Badrus dan Kina peka terhadap kebutuhan emosional Taufiq dan Tahmid, yaitu kebutuhan kasih sayang dari orang tua.

\section{Daftar Rujukan}

Ayun, Wawancara tanggal 12 Oktober 2019

Aziz, Rini. (2004). Jangan Biarkan Anak Tumbuh dengan Kebiasaan Buruk. Solo: Tiga Serangkai.

Badrus dan Kina, Wawancara tanggal 12 Oktober 2019

Faqih, Wawancara tanggal 12 Oktober 2019

Koentjoroningrat. (1989). Antropologi Sosial. Jakarta: Aksara Baru

Lestari, Sri. (2012). Psikologi Keluarga; Penanaman Nilai Dan Penanganan Konflik Dalam Keluarga. Jakarta; Kencana Prenada Media.

Mahmud, Ali Abdul Halim. (2004). Akhlak Mulia. Jakarta: Gema Insani.

Thoha, Chabib. (1996). Kapita Selekta Pendidikan Islam. Cet. 1. Yogyakarta: Pustaka Pelajar.

Tridonanto, Al. (2014). Mengembangkan Pola Asuh Demokratis. Jakarta: Elex Media Komputindo.

Kurniawan, Samsul dan Mahrus, Erwin. (2011). Jejak Pemikiran Tokoh Pendidikan Islam. Yogjakarta: Ar-Ruzz Media. 